\title{
Implementation of Non-Intrusive Jet Exhaust Species Distribution Measurements Within a Test Facility
}

DOI:

10.1109/AERO.2016.7500731

Link to publication record in Manchester Research Explorer

\section{Citation for published version (APA):}

Wright, P., Mccormick, D., Kliment, J., Ozanyan, K., Tsekenis, S., Fisher, E., McCann, H., Archilla, V., GonzálezNúñez, A., Johnson, M., Black, J., Lengden, M., Wilson, D., Johnstone, W., Feng, Y., \& Nilsson, J. (2016). Implementation of Non-Intrusive Jet Exhaust Species Distribution Measurements Within a Test Facility. In Aerospace Conference, 2016 IEEE IEEE. https://doi.org/10.1109/AERO.2016.7500731

\section{Published in:}

Aerospace Conference, 2016 IEEE

\section{Citing this paper}

Please note that where the full-text provided on Manchester Research Explorer is the Author Accepted Manuscript or Proof version this may differ from the final Published version. If citing, it is advised that you check and use the publisher's definitive version.

\section{General rights}

Copyright and moral rights for the publications made accessible in the Research Explorer are retained by the authors and/or other copyright owners and it is a condition of accessing publications that users recognise and abide by the legal requirements associated with these rights.

\section{Takedown policy}

If you believe that this document breaches copyright please refer to the University of Manchester's Takedown Procedures [http://man.ac.uk/04Y6Bo] or contact uml.scholarlycommunications@manchester.ac.uk providing relevant details, so we can investigate your claim.

\section{OPEN ACCESS}




\section{Implementation of Non-Intrusive Jet Exhaust Species Distribution Measurements Within a Test Facility}

\author{
Paul Wright \\ David McCormick \\ Joshua Kliment \\ Krikor Ozanyan \\ The University of Manchester \\ Oxford Road \\ Manchester, UK \\ +441613064785 \\ paul.wright@manchester.ac.uk \\ Mark Johnson \\ John Black \\ Rolls-Royce plc \\ Test and Measurement Engineering \\ Derby, UK, \\ +441332 247138 \\ Mark.Johnson3@Rolls-Royce.com
}

\author{
Stylianos-Alexios Tsekenis \\ Edward Fisher \\ Hugh McCann \\ School of Engineering \\ The King's Buildings \\ The University of Edinburgh \\ Edinburgh, UK \\ +441316505566 \\ h.mccann@ed.ac.uk
Michael Lengden
David Wilson
Walter Johnstone
University of Strathclyde
204 George Street
Glasgow, UK
+44 (0)141 5482641
w.johnstone@strath.ac.uk

\author{
Víctor Archilla \\ Álvaro González-Núñez \\ INTA, Turbojet Engine Test Centre \\ Ctra. Ajalvir, km 4. \\ Torrejón de Ardoz (Madrid), Spain \\ +34915201451 \\ archillapv@inta.es \\ Yutong Feng \\ Johan Nilsson \\ Optoelectronics Research Centre \\ University of Southampton \\ Highfield, \\ Southampton, UK \\ +442380 593101 \\ jn@orc.soton.ac.uk
}

\begin{abstract}
We report on the installation and commissioning of two systems for the measurement of cross-sectional distributions of pollutant species in jet exhaust, within the engine ground test facility at INTA, Madrid. These systems use optical tomography techniques to estimate the cross-sectional distributions of $\mathrm{CO}_{2}$ and soot immediately behind the engine. The systems are designed to accommodate the largest civil aviation engines currently in service, without obstruction of the exhaust or bypass flows and with negligible effect upon the entrained flow behavior. We describe the physical construction and installation status of each system. In the case of the $\mathrm{CO}_{2}$ system, we examine the challenges of achieving the structural rigidity necessary for adequate suppression of pointing error within 126 laser-based transmittance measurements, each utilizing a $7 \mathrm{~m}$ overall path length. We describe methods developed for efficient implementation of co-planarity and 4degree-of-freedom alignment of individual paths within this beam array. We also present laboratory performance data for three alternative optical designs that differ in their approach to the management of pointing error and turbulence-induced beam wander and spread. The FLITES soot monitoring capability is based on laser induced incandescence (LII) and uses a short-pulse fiber laser and two CCD cameras, in an autoprojection arrangement. We describe the measurement geometry currently being implemented in the test cell and discuss optical design issues, including once again the effect of the plume itself.
\end{abstract}

\section{TABLE OF CONTENTS}

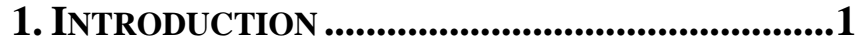

2. $\mathrm{CO}_{2}$ Measurement SySTEM ...........................2

3. SOOT MEASUREMENT SYSTEM .......................7

4. SUMMARY .......................................................9

ACKNOWLEDGEMENTS........................................10

REFERENCES...........................................................10

BIOGRAPHY ...........................................................11

978-1-4673-7676-1/16/\$31.00 @2016 IEEE

\section{INTRODUCTION}

We have reported previously on efforts by the FLITES consortium to introduce advanced optical diagnostics to the jet engine test environment [1]. The systems under development will provide non-intrusive measurements of the cross-sectional distributions of various pollutant species within the exhaust plume, immediately aft of the engine. At the time of writing, installation of systems for the quantification of $\mathrm{CO}_{2}$ and soot emissions is underway at the turboreactor facility of the Instituto Nacional de Tecnica Aeroespacial (INTA), on the outskirts of Madrid.

In this paper we focus on the optomechanical engineering aspects of these two systems and, in the case of the $\mathrm{CO}_{2}$ system, the means by which a precise optical system has been adapted for use in a large scale industrial process environment. Although the two systems have in common their use of both fiber laser technology and tomographic methods, the physical principles underpinning the measurements are very different and so each presents a unique set of challenges.

The $\mathrm{CO}_{2}$ measurement system is based upon optical tomography techniques developed by McCann and coworkers [2-9] and having much in common with the X-ray computed tomography ('CT') systems used in many hospitals. The required optical transmittance measurements are made along an intersecting grid of paths defining the measurement plane.

The soot measurement system is based upon the combination of laser induced incandescence (LII) measurement [10-15] with autoprojection techniques previously used in fluorescence tomography $[16,17]$. The measurement plane in this case is defined by mechanically scanning the excitation laser's beam across the plume. 
Both systems are susceptible to the scattering effects of the hot, turbulent exhaust plume. We have undertaken preliminary laboratory and field tests to better understand these effects and to evaluate candidate mitigation strategies for the $\mathrm{CO}_{2}$ measurement system [18].

It is essential that neither system is intrusive to the normal operating characteristics of the engine or test cell. Their structures must therefore be located outside regions of significant exhaust, bypass or entrained flow. In the case of the $\mathrm{CO}_{2}$ measurement system, this has necessitated significant computational fluid dynamics (CFD) modelling of the impact of the system's annular support 'ring' on flow behavior within the test cell (see Section 2). Within the test bed, the engine is mounted on a pylon similar to those used on wing and typically fitted with an aerodynamic fairing. Both systems' measurement planes are located slightly downstream of the trailing edge of this fairing, immediately prior to the exhaust flow's entry into the detuner (augmentor) duct. This location is intended to provide the earliest access to the exhaust flow consistent with being non-intrusive.

In this paper, the $\mathrm{CO}_{2}$ and soot measurement systems are described in Sections 2 and 3 respectively.

\section{2. $\mathrm{CO}_{2}$ MeAsurement SySTEM}

\section{Overview}

The $\mathrm{CO}_{2}$ measurement system utilizes 126 transmittance measurement paths arranged in an intersecting grid, optimized according to methods outlined in [19]. The region of greatest intersection extends slightly beyond the 'plume space' occupied by the hot exhaust flow. To meet the requirement for non-intrusive measurement, the launch and receive elements associated with each path must be located far from the plume, in the periphery of the entrained flow. Implementation of such a transmittance measurement grid requires a large and substantially rigid mounting 'ring' structure, with sufficient clear aperture to allow essentially unimpeded passage of the exhaust, bypass and entrained flows. In practice, a $7 \mathrm{~m}$ overall path length is used, of which no more than $1.4 \mathrm{~m}$ is within the exhaust plume. Figure 1 illustrates the approximate extent of the exhaust and bypass flow regions within the ring structure. CFD modelling (described under Cell CFD below) has been used to assess the perturbing effect of the ring on the entrained flow and hence verify the acceptability of this arrangement. This modelling also provided estimates of the flow-derived loading to which the ring will be subjected.

At almost 4 metric tonnes, over $7 \mathrm{~m}$ edge-to-edge and nearly $2 \mathrm{~m}$ deep, the scale of the ring structure presents several logistical challenges. Its size means that it must either be fabricated in-situ or constructed in a modular fashion. A key consideration here is the time taken to commission the system once it is introduced into the test cell. Test cell time is expensive and often pressured, therefore an installation paradigm that allows the duration of in-cell operations to be minimized is essential. In situ fabrication was therefore discounted and efforts concentrated on achieving and maintaining the high degree of alignment necessary for a transmittance measurement within a potentially less rigid modular structure. This ex situ approach also requires that the majority of the time-consuming alignment processes be undertaken outside of the test cell.

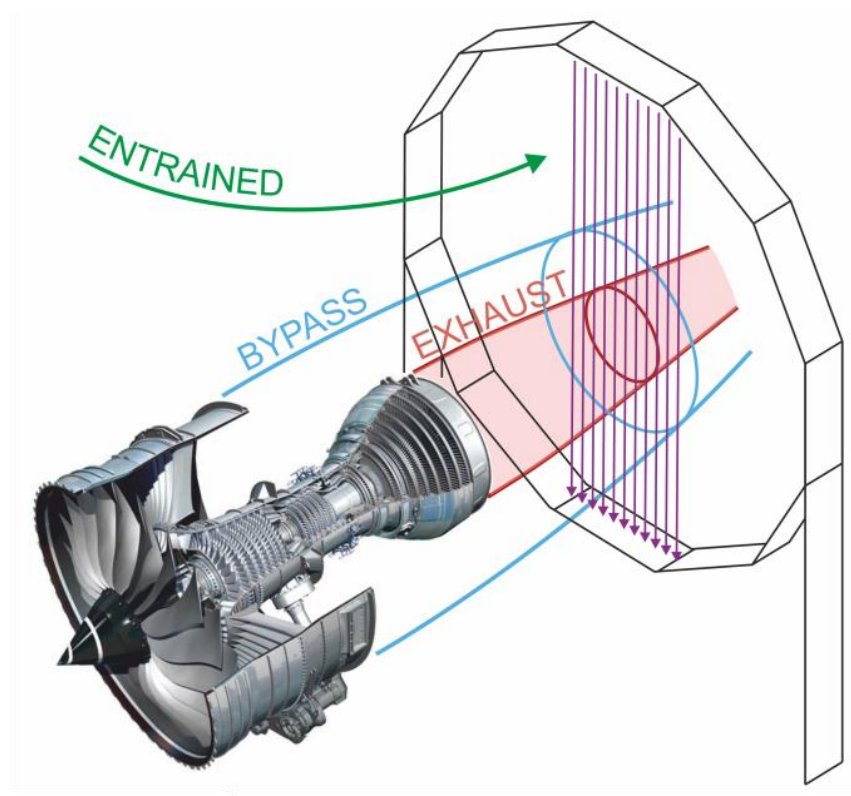

Figure 1 - Dodecagonal mounting 'ring' for $\mathrm{CO}_{2}$ measurement system showing approximate extent of exhaust and bypass flows and their intersection with one projection (Trent engine cutaway (C) Rolls-Royce plc) adapted from [1].

During this preliminary alignment, the ring is in the horizontal orientation used for its assembly, with multiple points of support. A particular concern is therefore the deflection of the ring structure when moving from this assembly / alignment situation to its, vertically-oriented and edge supported, operational position. A tiered approach has been adopted in which the ring structure serves as the foundation for 12 independently adjustable support plates, which provide the mounting surfaces for 126 pairs of launch and receive modules. Each support plate is highly rigid and includes dedicated alignment aids, as described under Support Plate Design. This should allow the relative alignment of the 12 support plates to be quickly restored to that prevailing during the horizontal alignment process, following the ring's installation in the test cell, minimizing the need for further realignment. Distortion of these support plates under load, vibration and thermal expansion has been simulated, as has the mechanical behavior of the ring itself, as described under Ring Structure. Figure 2 shows the ring, support plates, and optical launch and receive modules, ready for preliminary alignment. 


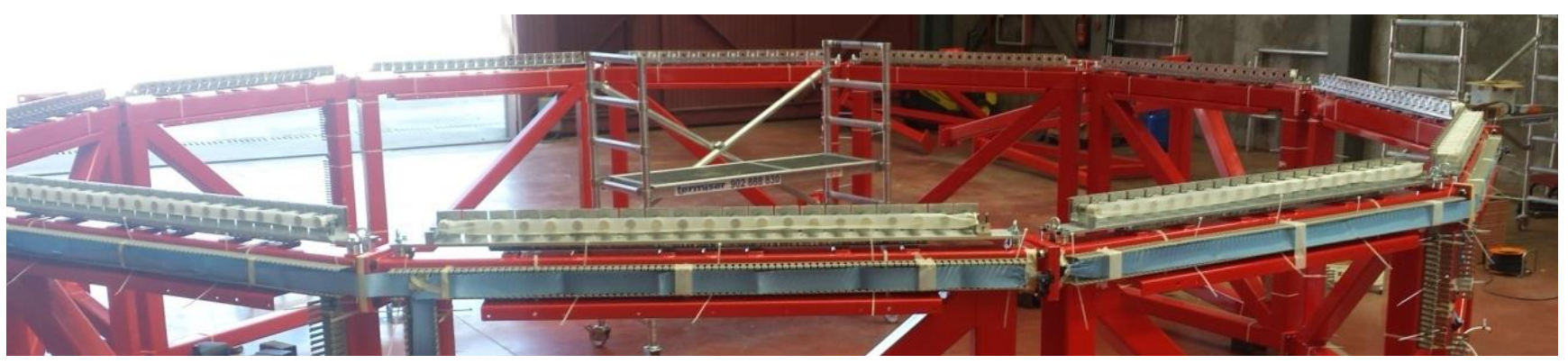

Figure 2 - Ring, support plates and optical modules during initial assembly in horizontal orientation

The optical and optomechanical design of the individual Launch and Receive Modules allows pan and tilt adjustment of the pointing directions within each module pair, as well as the flexibility to explore the alternative mitigation strategies suggested in [18]. No study of which we are aware has allowed us to definitively predict the optimum optical design strategy and addressing this issue will form part of our experimental study.

\section{Ring Structure Design \& Evaluation}

The ring elements are fabricated from hot-rolled mild carbon steel (alloy S275JR). Bolted flanges with dowels are used to achieve far better assembly repeatability than is typical of such fabricated steel structures. The restricted clearance between the flow and other test cell structures limits the ring's radial extent but its substantial depth along the plume and latticed construction aid torsional rigidity.

The ring structure was refined using both static and modal analysis of various candidate designs. The ring's shape was optimized to meet static deflection targets of less than $537 \mu \mathrm{rad}$ and $1.8 \mathrm{~mm}$, assuming a frontal load of $9 \mathrm{kN}$, uniformly distributed over the ring. These targets were derived from simple estimates of the effect of misalignment on eventual measurement performance. Modal analysis of the ring identified potential resonances at $2.9 \mathrm{~Hz}$ and $8.3 \mathrm{~Hz}$; the latter is shown in Figure 3. Harmonic analysis, based on experimental measurements of the forcing vibration and noise signatures within the test cell, was then used to determine the extent to which these modes may be excited.

\section{Cell CFD}

CFD results suggest that the disturbance to the entrained flow is modest and quite localized, with little impact on the wider flow characteristics of the cell (Figure 4). The overall structural load imposed on the ring by the flow is surprisingly small, partly due to the balanced nature of the forces involved, with a net axial loading of less than $600 \mathrm{~N}$ predicted. The small magnitude of these forces, relative to the static loads within the structure, suggests that flow loading is unlikely to perturb the ring significantly. The predicted flow speeds in the vicinity of the optical launch and receive elements (not modelled) are in the range $5-15 \mathrm{~m} \mathrm{~s}^{-1}$.

\section{Support Plate Design}

The ensemble of support plates effectively implement an annular optical table onto which the desired combination of optical modules can be fitted. A total of 12 plates are

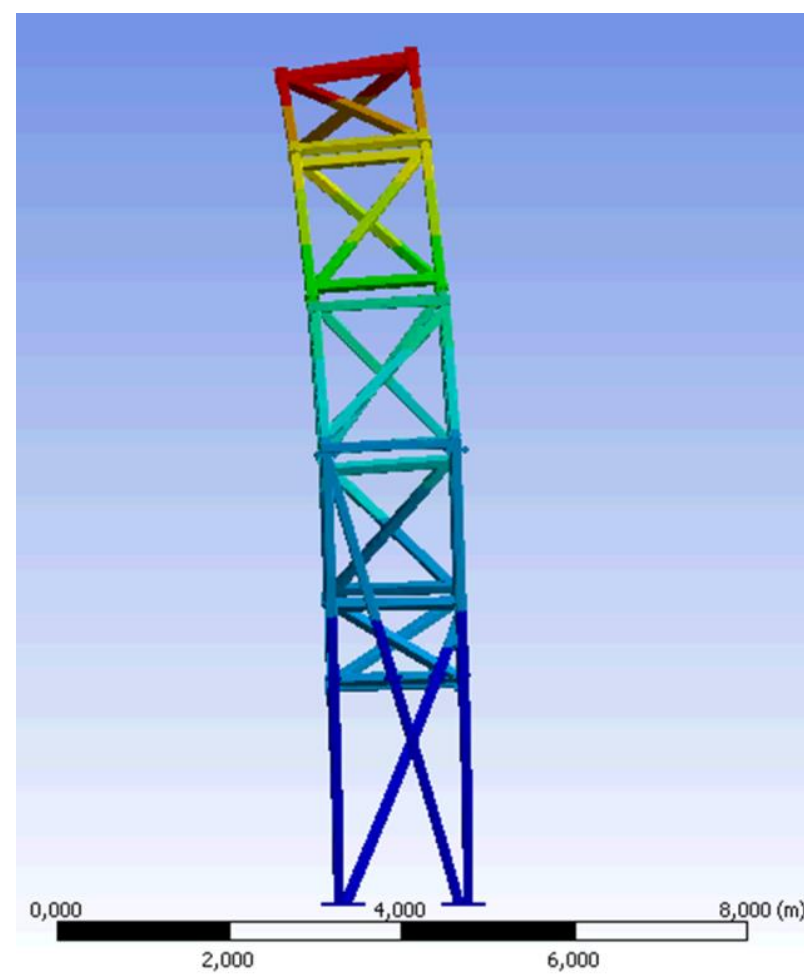

Figure $3-8.3 \mathrm{~Hz}$ mode of ring structure.

mounted on the dodecagonal ring structure, one per side. Opposing pairs of plates form one tomographic projection, each comprising 21 beam paths. Modularity was a key objective in the support plate design, allowing replacement or substitution of launch and receive modules with a minimum of downtime.

The rigidity of the support plates is of great importance in the control of pointing errors, especially those arising following the transfer to the vertical orientation. The support 


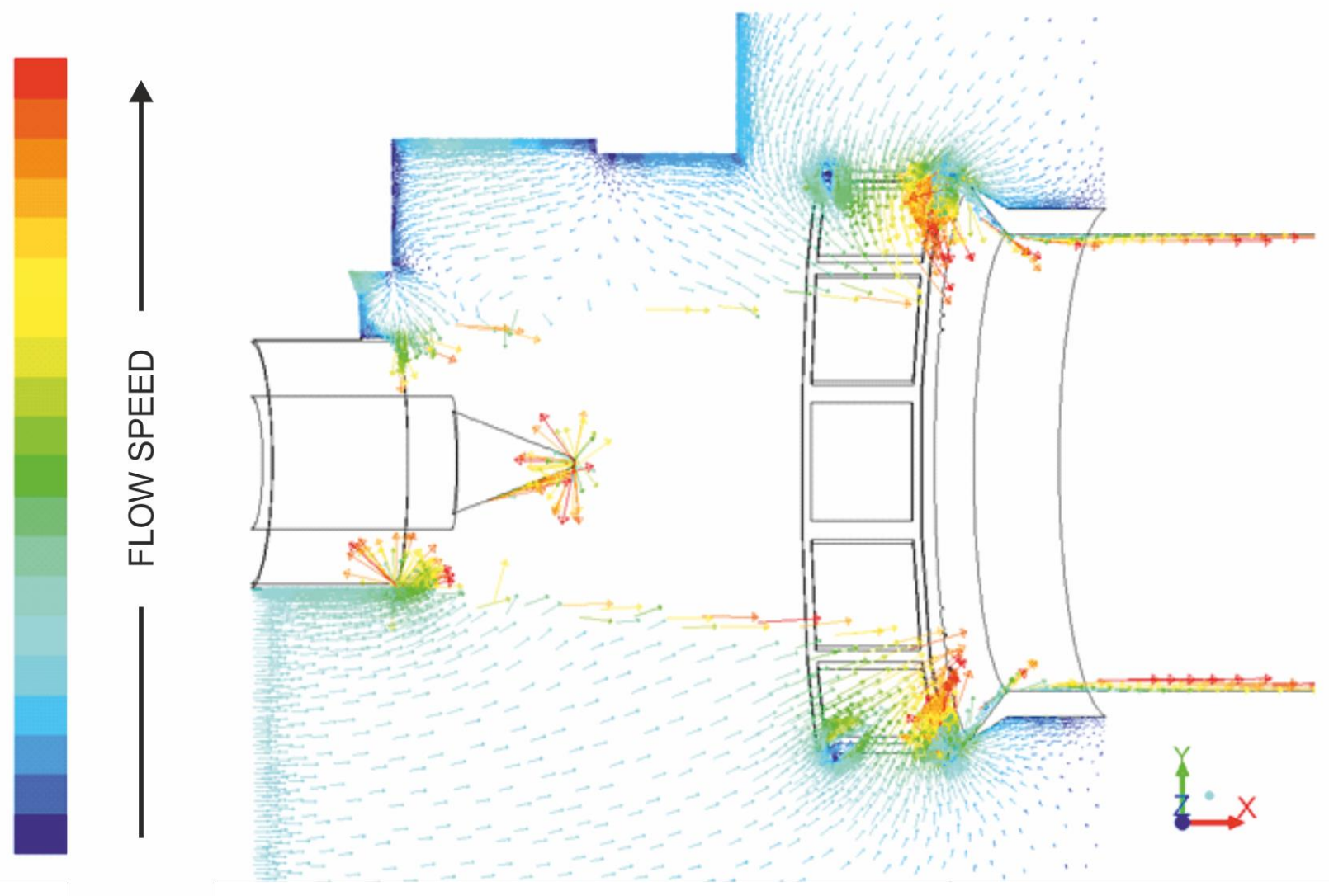

Figure 4-CFD predicted velocity vectors

plates can be considered as long beams, rigidly fixed at both ends. A number of bending moments can arise in this configuration, sagging and torsional bending (twisting) being of particular importance. Sagging is exacerbated by gravity during system assembly, when the ring is horizontal, potentially contributing to orientation sensitivity. Torsional bending is more likely to result from excitation of the natural frequencies of the structure when exposed to the high-vibration environment of the test cell.

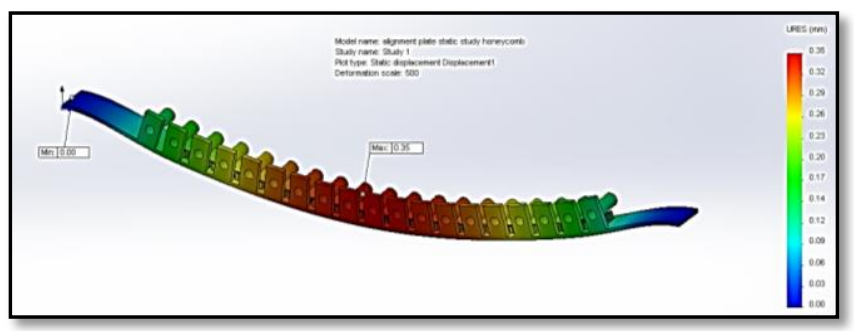

Figure 5 - Gravitational deflection of support plate in horizontal (alignment) orientation. Sag (exaggerated 500 times) is substantial $(0.35 \mathrm{~mm})$ but relatively benign.
A series of finite element simulations were performed using the Linear Stress Analysis suite in SOLIDWORKS in order to study the effects of static loading of the plates by the optical modules under gravity. The objective was to identify a suitable structure that would sufficiently stiffen the plates for the maximum sagging under gravity to be less than 1 $\mathrm{mm}$ with the ring in the horizontal orientation. A number of stiffening structures were evaluated, including ' $L$ ', ' $U$ ' and square-shaped aluminum sections mounted under the plate. The plate thickness was also varied; however, none of the above structures achieved the target stiffness.

A composite, combining a $10 \mathrm{~mm}$ thick extruded $6082 \mathrm{~T} 6$ aluminum component mounting surface with a standardsized honeycomb structure (Easy Composites, $6.4 \mathrm{~mm}$ cell, $15 \mathrm{~mm}$ thick), and a $3 \mathrm{~mm}$ aluminum rear 'skin' plate, was found to meet the specification, with a predicted maximum deflection of $0.35 \mathrm{~mm}$ (Figure 5). The simulation was repeated for the vertically oriented case, indicating a smaller deflection of $80 \mu \mathrm{m}$ but with significant torsion (Figure 6). The pointing error arising from this torsional strain is sufficient to require realignment of the launch and receive elements but this should be limited to a 'fine-tuning' process, based on signal maximization, and far less time- 
consuming than full alignment of an (invisible) infrared beam.

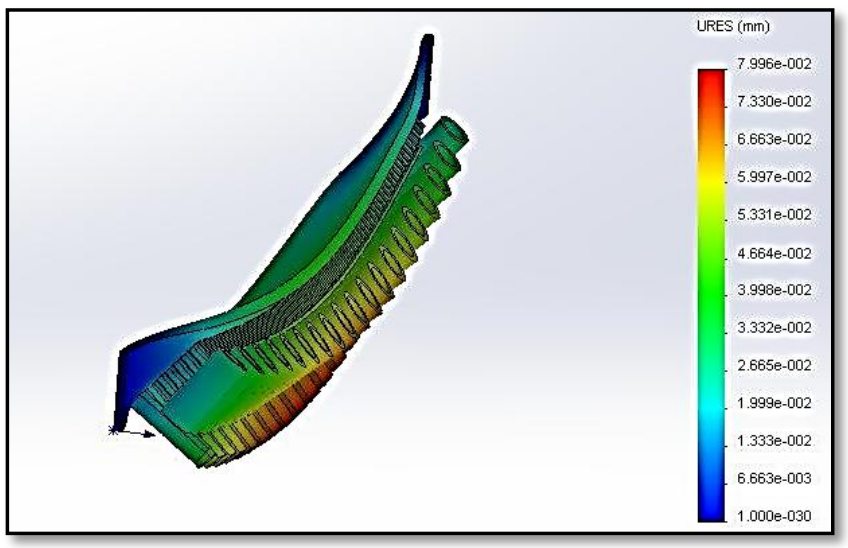

Figure 6 - Gravitational deflection of support plate in vertical (operating) orientation. Strain is small $(0.08 \mathrm{~mm})$ but its torsional nature suggests nonnegligible pointing error. Plot is exaggerated 2397 times.

A study into the thermal expansion of the support plates was performed, motivated by the substantial length of the plates and the broad ambient temperature range in the Madrid test facility. The study was performed by finite element simulation using the Flow Simulation suite in SOLIDWORKS. The plate was rigidly attached to one end face and allowed to thermally expand. The ambient and plate reference temperature was set to $0^{\circ} \mathrm{C}$. The ambient temperature was then set to $50^{\circ} \mathrm{C}$. The optical modules were not included in the simulation.

This thermal simulation proved to be extremely valuable, identifying a potentially serious but avoidable design issue. The array of dowel and machine screw holes, used for mounting the optical modules, was found to promote almost $4 \mathrm{~mm}$ bending of the plate under thermal expansion (Figure 7). This was found to be largely mitigated by the addition of a set of dummy mounting holes, mirrored about the plate's centerline. Differential expansion of the plate and ring is accommodated using slot mounting at one end of each support plate.

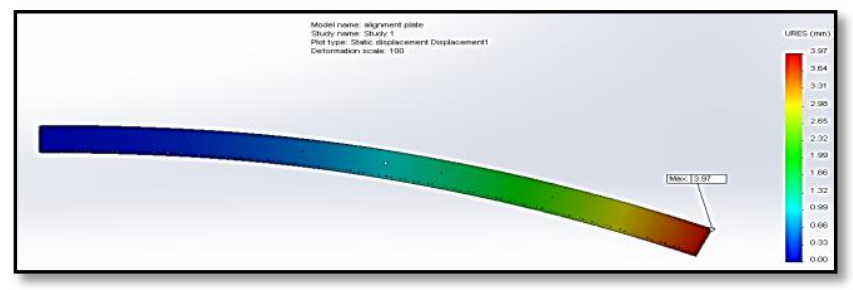

Figure 7 - Support plate distortion under thermal expansion.

Modal analysis of both the ring and the support plate structure was undertaken to highlight potential vibrational sensitivity. The support plates show four significant resonant modes, at 23, 65, 81 and $123 \mathrm{~Hz}$, but these do not coincide with those of the ring, which mostly lie below $15 \mathrm{~Hz}$. The $65 \mathrm{~Hz}$ mode is illustrated in Figure 8.

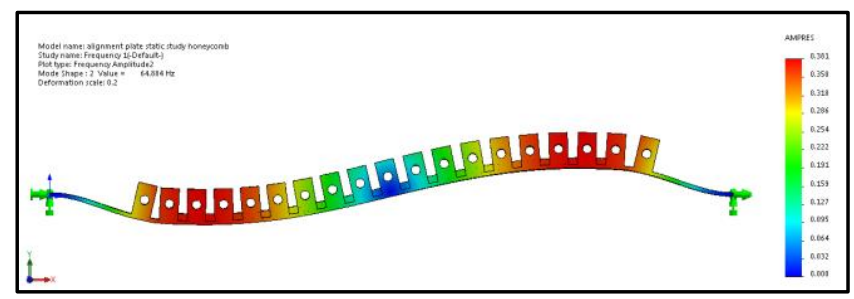

Figure 8-Support plate resonant mode at $65 \mathrm{~Hz}$.

The completed support plates are $100 \mathrm{~mm}$ high and 1800 $\mathrm{mm}$ long, and feature composite stiffening of the central $1200 \mathrm{~mm}$. The component mounting surface suffered from extrusion lines and other defects, necessitating careful selection of raw material and post-machining wet-sanding to achieve acceptable flatness and roughness. The interface to the optical modules combines dowels having a snug transition fit, per ISO K7h6, and sizeable machine screws to achieve precise and stiff mounting. The optical modules are mounted on a $75 \mathrm{~mm}$ pitch, with launch and receive alternated to minimize the possibility of inter-beam crosstalk. 23 mounting points are available on each support plate, allowing each projection to be expanded by $150 \mathrm{~mm}$ to meet the needs of future, larger engines.

\section{Support Plate Alignment}

The ability to rapidly establish or restore coplanarity of all 12 support plate mounting surfaces is essential to our proposed installation paradigm. Additionally, it must be possible to quickly translate and orient the support plates within this plane to align the ends of each projection. To this end, each support plate incorporates an alignment system, comprising a mounting for a visible laser source and a pinhole target.

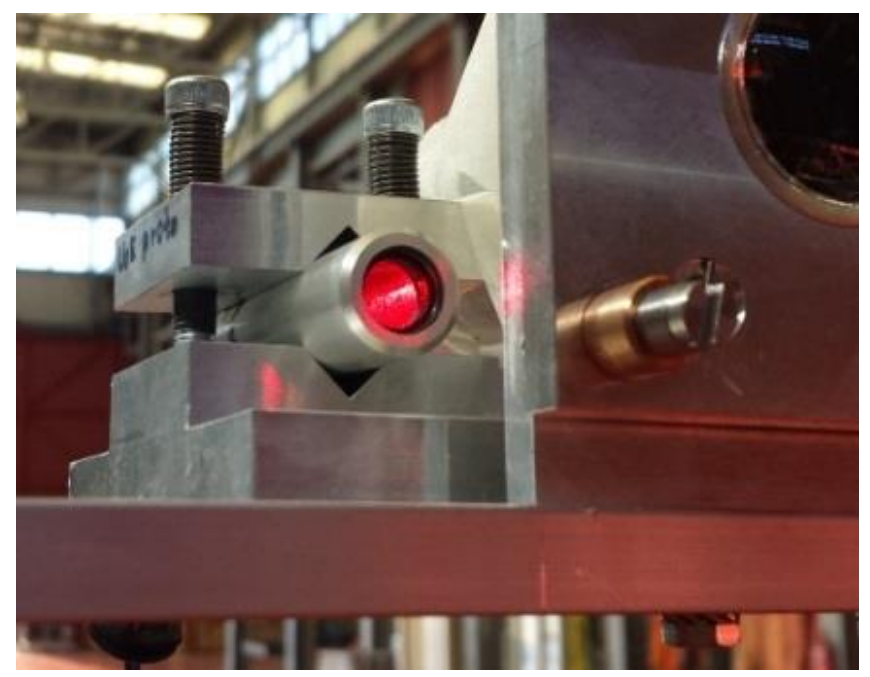

Figure 9 - Alignment laser in vee-mount. The adjacent optical module and the $10 \mathrm{~mm}$ deck of the support plate can also be seen. 


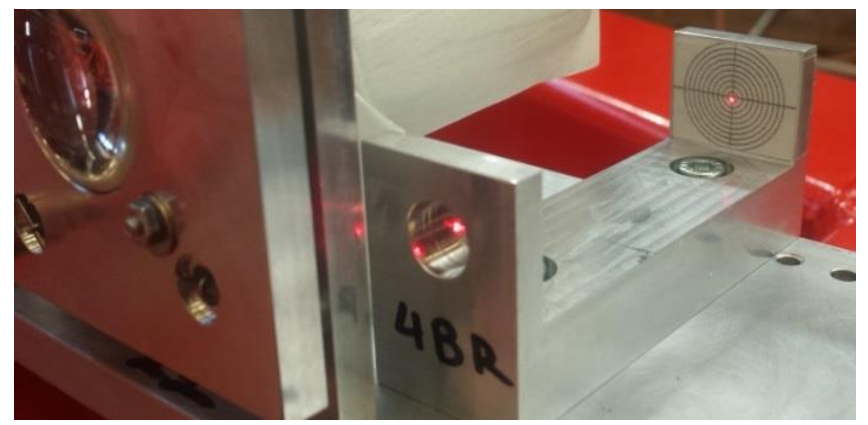

Figure 10 - Pinhole and target arrangement in use.

A high-quality diode laser, intended for surveying applications, is mounted on the left-end of the support plate in a mechanically stiff spring-loaded vee-mount (Figure 9). The $0.5 \mathrm{~mm}$ pinhole is mounted on the right-end, $70 \mathrm{~mm}$ in front of a concentric circle target (Figure 10). The pinhole and the target are accurately aligned within a single machined part. This effectively forms a double-pinhole arrangement, enabling rapid alignment. Both the vee-mount and the pinhole target are positioned and secured on the support plate similarly to the optical modules. Besides the laser sources, all parts of the alignment mechanism remain permanently affixed to the plates.

Considering the opposing support plates within one projection, the visible laser source of each plate illuminates the pinhole assembly on the other. The alignment procedure involves repositioning the support plates until each laser beam passes through its opposing pinhole aperture and illuminates its target. The plates are adjusted until both lasers illuminate the centers of the targets by the introduction of shims under the four mounting points to control the elevation, pitch, yaw and roll. Securing bolts are then fastened. The small acceptance angle of the doublepinholes coupled with their positioning on the plates results in the plates being both co-planar and parallel following this alignment procedure, illustrated in Figure 11.

\section{Launch and Receive Modules}

The launch and receive modules provide fine alignment of the launch and receive directions, as well as adjustment of the focusing regime, to allow the exploration of strategies for the mitigation of scattering effects . The launch modules interface to standard FC/APC connectorized single-mode optical fibers. Each receive module incorporates an extended InGaAs photodiode, appropriate to the $1997 \mathrm{~nm}$ working wavelength, and a high-performance differential transimpedance amplifier and line-driver combination.

Optomechanically, both module types have much in common with the three-point kinematic mounts found in the majority of optics labs but their design boasts additional features, rendering them suitable for test cell use. In comparison to standard mounts, they use much stronger springs and deeper alignment grooves, and include a true (opposed screw) locking mechanism that is not reliant on the springs. The focus adjustment is spacer-based and does not require rotation of either the launch fiber or the receiver electronics. A cutaway model of one launch-receive pair is shown in Figure 12.

The optical design of the modules is intended to maximize the quality of the electrical signals obtained at the photodiode outputs. The design must consider not only geometric effects, such as pointing error arising in the structure, but also optical noise mechanisms. Light propagation through jet exhaust is particularly susceptible to the scattering effects of the hot, turbulent gas, leading to time-varying beam wander and spread [20]. Aperture averaging [21] can be an important source of scintillation reduction but collecting a sufficiently high proportion of the beam energy on a relatively small photodiode is challenging.
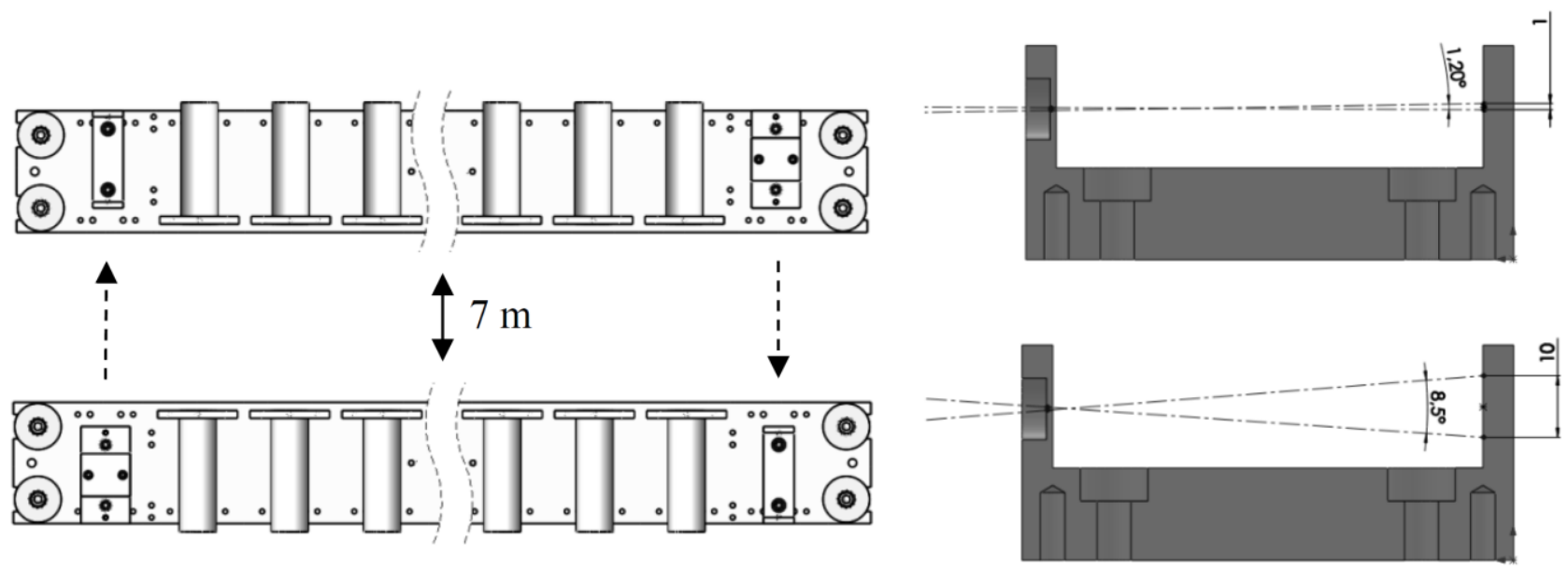

Figure 11 - Support plate alignment process. The locations of the vee-mounts and pinhole target assemblies can be seen at either end of the two opposing support plates. At the $7 \mathrm{~m}$ working distance, a well-aligned beam on the target corresponds to alignment accuracy of better than 1 degree. 


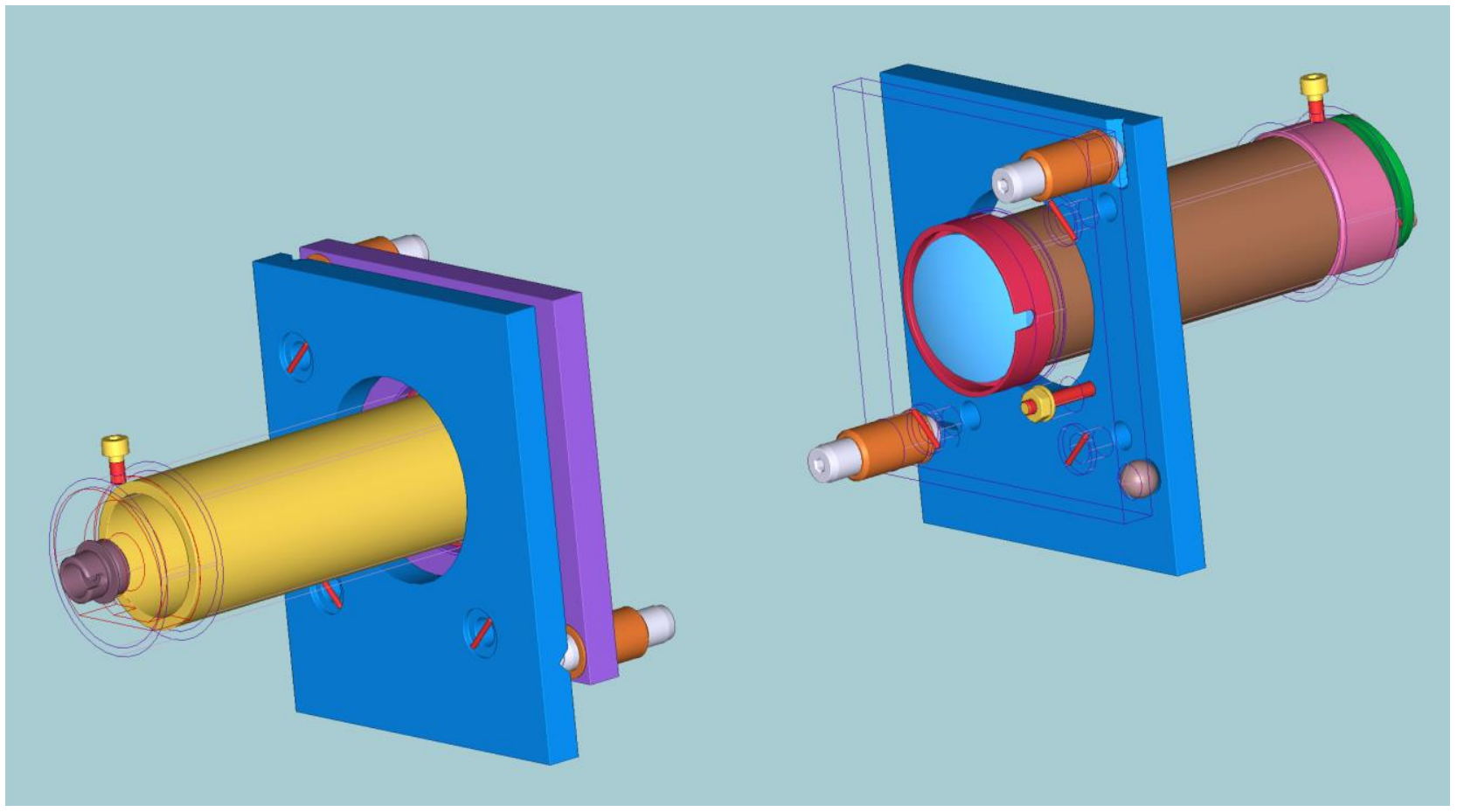

Figure 12 - Optical module launch-receive pair. The shared 'enhanced kinematic mount' architecture can be seen in both modules, as can the spacer-based focus control (yellow/brown tubular elements).

In this context, we have investigated the relative effectiveness of optical designs based on collimated, focal and divergent plume intersection in laboratory phantoms (Figure 13 - adapted from [22]). Although the phantom system used has a somewhat different balance of beam wander and spread to that expected in jet exhaust, these results support the theoretical argument that a mid-plume focus should allow the benefits of full aperture averaging to be realized using a smaller detector. They also indicate that divergent launch schemes, intended to mitigate pointing error, are highly susceptible to scintillation noise in coherent systems.

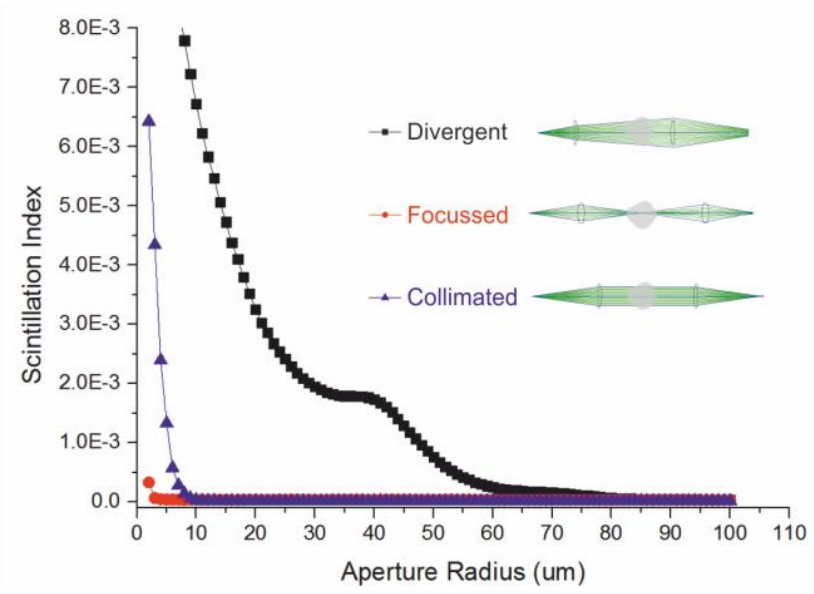

Figure 13 - Scintillation suppression performance of three alternative optical designs.
Within this non-imaging and highly paraxial optics problem, there is little advantage in the use of aspheric surfaces, even before plume-derived scattering is considered. Plano-convex spherical lenses of focal length $75 \mathrm{~mm}$ are used. Refractive optics were preferred, with the lenses acting as protection windows for the launch fiber or detector. Tilting of the APC launch ferrule and the InGaAs detector provide suppression of etalon noise.

\section{SoOt Measurement System}

\section{Overview}

Laser Induced Incandescence (LII) is a well-established method for soot measurement. Its early application in aeroengines focused on using Q-switched Nd:YAG lasers with short pulse durations, typically $\sim 10 \mathrm{~ns}$, and low pulse repetition rates (PRR), typically of the order of $10 \mathrm{~Hz}$ [1214]. More recent work has suggested the higher powers and longer-pulse durations afforded by fiber-lasers offer potential gains in measurement sensitivity [23]. Experiments on a live engine have demonstrated in-situ soot particle sensing in an aero-engine using a long-pulse fiberlaser operating at high PRR $(>10 \mathrm{kHz})$ [15]; however, further work is required to better understand the thermodynamics of long-pulsed LII before calibration of a system to measure soot volume fraction will be possible.

Measurement of soot in a 2D imaging plane can be achieved with LII by scanning the laser beam through a cross-section of the plume. Previous LII studies on aero-engines have 


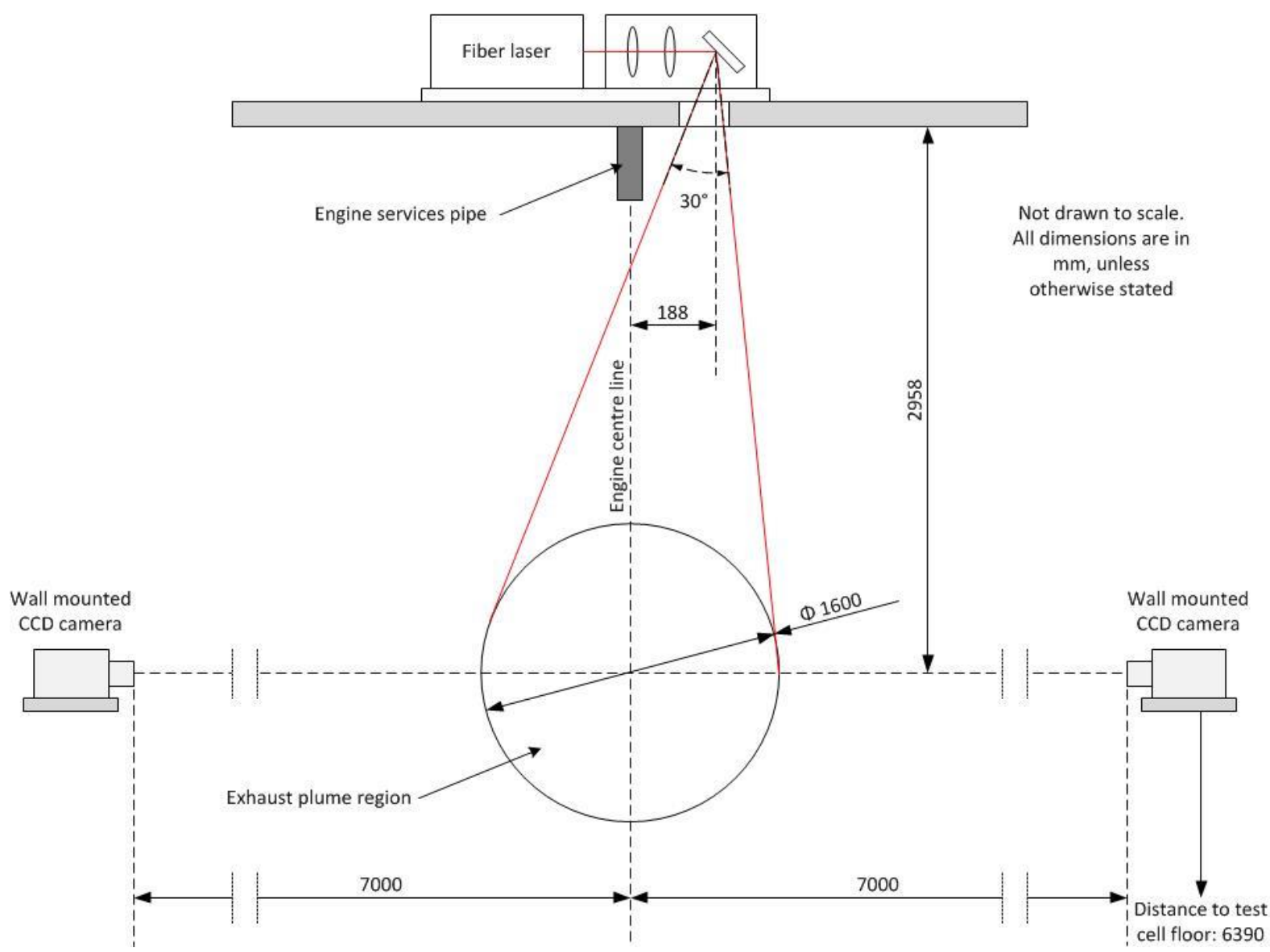

Figure 14 - Schematic illustrating the imaging geometry used by the FLITES LII system in the INTA test cell facility.

achieved this using a scanning mirror with light-collection in a backward scattering configuration [12]. Such an arrangement yields the angular distribution of soot derived incandescence in the plane of the scanned beam. However, it does not create a true 2D cross-sectional image of soot concentration. We have previously proposed AutoProjection Tomography (APT) as a method to generate 2D images of soot distributions, as described in [1]. The principle of APT is that a 'near-orthogonal' arrangement of excitation and detection within a common plane permits spatially resolved measurements to be obtained in a multipath system; accumulation of these spatially resolved measurements can be built into a $2 \mathrm{D}$ image without the complex inversion step, typical of most optical tomography methods $[16,17]$. APT differs from the established Planar Laser-Induced Fluorescence (PLIF) in that access to the imaging domain is only required in a single optical plane, making it ideal for use in the constrained 'thin-slice' available between the engine and detuner.

Research into APT has typically employed collimation of the source and detection paths to spatially resolve the parameter of interest; however, we propose the use of widefield detection using suitably calibrated cameras. The FLITES LII system implements its 'near-orthogonal' APT geometry using an excitation laser, sited above the exhaust plume of an aero-engine, and two wall-mounted cameras, located axially on the engine horizontal center line. This configuration is 'near-orthogonal' in so far as the excitation laser beam is scanned through a $30^{\circ}$ angle across the plume, which subtends an angle of around $13^{\circ}$ at each camera (Figure 14). The intersection the excitation and detection ray paths is therefore, in general, only approximately orthogonal. Note the asymmetry caused by some of the engine service piping, forcing the laser to be offset with respect to the engine's centerline. A CAD model illustrating the location of the LII laser and cameras within the engine test cell is shown in Figure 15.

\section{Excitation laser and scanning head}

The source laser is a bespoke 3-stage $\mathrm{Yb}$-doped fiber MOPA producing $\approx 20 \mathrm{~ns}$ laser pulses at $1060 \mathrm{~nm}$ with peak pulse power of $500 \mathrm{~kW}, 110 \mathrm{~W}$ average power and PRR of $10 \mathrm{kHz}$. The laser output is directed via a focusing telescope and scanning head mirror across the engine exhaust plume through an opening in the gantry. The focusing telescope is comprised of two rail-mounted lenses around $300 \mathrm{~mm}$ apart. These lenses can be adjusted to create a weakly focused beam profile with confocal length greater than the diameter 
of the exhaust plume. Previous experiments on aero-engines have shown that the laser fluence in the plume should fall in the range 0.2 to $1.2 \mathrm{~J} \mathrm{~cm}^{-2}[13,15]$, the upper limit representing the vaporization threshold. First order calculations indicate a beam waist diameter of 1-2 mm, although this could be increased whilst maintaining the necessary fluence as the laser's potential power output is not fully utilized at present. Optical scattering will act to reduce the beam's fluence as it propagates across the plume.

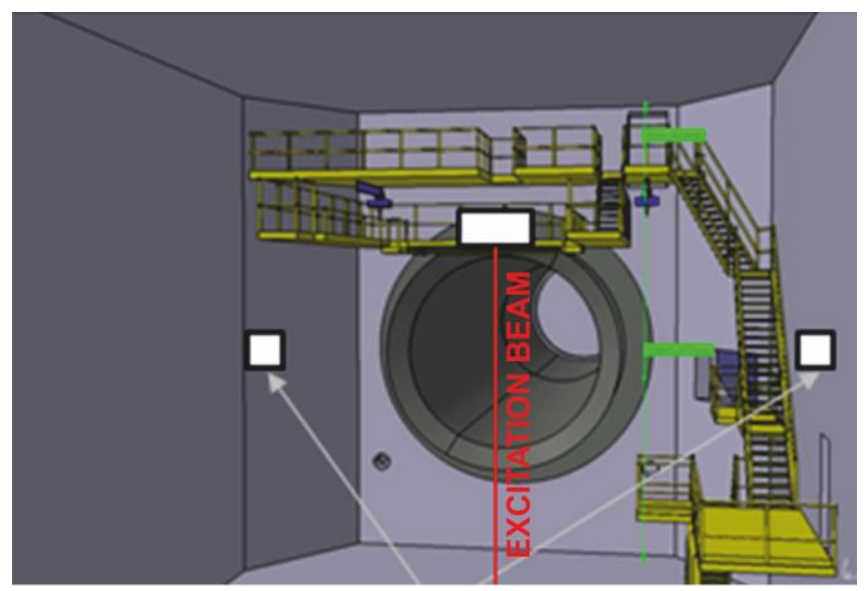

CAMERAS

Figure 15 - Model of the engine test cell showing the location of the gantry-mounted excitation laser and wallmounted cameras.

Literature leads us to expect perhaps as much as $1 \mathrm{mrad} \mathrm{rms}$ beam spread from this mechanism [20]. The focusing telescope and total laser power will be adjusted to minimize fluence variation along the excitation beam. The scanning head will be implemented with a stepper motor driving a mirror to achieve the required $30^{\circ}$ scanning range at a minimum $1^{\circ}$ resolution. Characterization and development of the scanning head is ongoing and details will be reported in a later publication.

\section{Cameras}

The detection channel implements wide-field detection using two LaVision E-lite 2M cameras with 1626 pixels in the vertical plane, i.e. along the laser beam path. The cameras are fitted with $90-105 \mathrm{~mm}$ focal length lenses which provide a $1.5-1.7 \mathrm{~m} \mathrm{FOV}$ at $7 \mathrm{~m}$ from the imaging plane which translates to around $1 \mathrm{~mm}$ per pixel in the vertical image plane. The cameras are synchronously triggered by a LaVision PTU-X synchronization unit, which provides a $5 \mathrm{~V}$ TTL-trigger to each camera. Data from the cameras are transferred to a host PC located in an adjacent control room over Ethernet, via a Netgear ProSAFE Gigabit 24 port switch. Control of the synchronization unit is also via Ethernet with USB-RJ45 converters used on both the synchronization unit and host PC. Although the Ethernet switch is shared with the $\mathrm{CO}_{2}$ measurement system, 6 of its ports are configured as a VLAN dedicated to the LII system.

\section{Location and Logistics}

The laser system (including the associated power supplies, telescope and scanning head), synchronisation unit, and Ethernet switch are located on the gantry above the engine exhaust plume. The cameras are mounted on mounting plates affixed to the test cell walls $6390 \mathrm{~mm}$ above floor level, on the engine's horizontal centerline. As the cameras are only accessible from a cherry picker, they too must be controlled remotely. The Class 4 laser beam will be terminated in a floor-level beam dump over the full scan width. The design of this beam dump must include a means to prevent accumulation of unburned fuel, which would otherwise constitute a fire hazard.

\section{SUMMARY}

Installation of the FLITES tomographic exhaust $\mathrm{CO}_{2}$ measurement system at INTA's Madrid jet engine test facility is in progress and final preparations are being made for the introduction of the LII-based soot measurement capability.

We have described the mechanical and optical design efforts which underpin the former installation. These include flow simulation to establish the acceptability of the measurement system within the test cell, finite element modelling of the mechanical behavior of both the ring and the support plates, and the design of custom optomechanics, suitable for use in this environment. A hierarchical method has been developed that will allow rapid realignment of the beam paths, following the inevitable changes arising following the system's transfer into the test cell. The optical design is being optimized, considering the effects of both pointing errors and scintillation effects attributable to the turbulent exhaust flow, but a final decision on the optimum solution will depend on the results obtained during engine tests. At the time of writing, support plate alignment, on a horizontally oriented ring, is complete and preliminary alignment of the individual launch and receive pairs is about to commence.

The current objective for the FLITES LII system is initial demonstration of both fixed and scanned measurements of soot concentration on a large-scale gas turbine engine in a test facility. The initial challenges are a demonstration of the feasibility of using the new Yb-doped fiber MOPA laser developed in the FLITES project for in-situ LII, and a first demonstration of the principle of LII-APT as an imaging methodology for particulate measurements in gas turbine engines.

The soot measurement system does not present the same optomechanical alignment challenges as the $\mathrm{CO}_{2}$ system. All equipment is located outside of the primary and entrained air flows within the test cell and the use of camera-based detection eliminates the need for precise optical alignment of the detectors with the scanning plane of the excitation beam. Longer term objectives for the soot 
measurement system center on further development of the LII architecture presented above and overcoming the significant difficulties of calibrating the LII signal to obtain reliable and accurate measurement of soot volume fraction.

We anticipate first results from both the $\mathrm{CO}_{2}$ and soot measurement systems within 2016.

\section{ACKNOWLEDGEMENTS}

The authors wish to acknowledge the industrial partners within the FLITES consortium (see flites.eu) for their many contributions to the project. This work is funded by the UK Engineering \& Physical Sciences Research Council.

\section{REFERENCES}

[1] P. Wright, D. McCormick, K. Ozanyan, M. Johnson, J. Black, E. Fisher, et al., "Progress towards non-intrusive optical measurement of gas turbine exhaust species distributions," in Aerospace Conference, 2015 IEEE, 2015, pp. 1-14.

[2] S. J. Carey, H. McCann, F. P. Hindle, K. B. Ozanyan, D. E. Winterbone, and E. Clough, "Chemical species tomography by near infra-red absorption," Chemical Engineering Journal, vol. 77, pp. 111-118, Apr 152000.

[3] F. P. Hindle, S. J. Carey, K. Ozanyan, D. E. Winterbone, E. Clough, and H. McCann, "Measurement of gaseous hydrocarbon distribution by a near-infrared absorption tomography system," Journal of Electronic Imaging, vol. 10, pp. 593-600, Jul 2001.

[4] F. P. Hindle, S. J. Carey, K. B. Ozanyan, D. E. Winterbone, E. Clough, and H. McCann, "Near infra-red chemical species tomography of sprays of volatile hydrocarbons," Technisches Messen, vol. 69, pp. 352357, Aug 2002.

[5] P. Wright, K. B. Ozanyan, S. J. Carey, and H. McCann, "Design of high-performance photodiode receivers for optical tomography," IEEE Sensors Journal, vol. 5, pp. 281-288, Apr 2005.

[6] P. Wright, C. A. Garcia-Stewart, S. J. Carey, F. P. Hindle, S. H. Pegrum, S. M. Colbourne, et al., "Toward in-cylinder absorption tomography in a production engine," Applied Optics, vol. 44, pp. 6578-6592, Nov 1 2005.

[7] N. Terzija, J. L. Davidson, C. A. Garcia-Stewart, P. Wright, K. B. Ozanyan, S. Pegrum, et al., "Image optimization for chemical species tomography with an irregular and sparse beam array," Measurement Science \& Technology, vol. 19, Sep 2008.
[8] P. Wright, N. Terzija, J. L. Davidson, S. Garcia-Castillo, C. Garcia-Stewart, S. Pegrum, et al., "High-speed chemical species tomography in a multi-cylinder automotive engine," Chemical Engineering Journal, vol. 158, pp. 2-10, Mar 152010.

[9] N. Terzija, S. Karagiannopoulos, S. Begg, P. Wright, K. Ozanyan, and H. McCann, "Tomographic imaging of the liquid and vapour fuel distributions in a single-cylinder direct-injection gasoline engine," International Journal of Engine Research, vol. 16, pp. 565-579, Jun 2015.

[10] L. A. Melton, "Soot diagnostics based on laser heating," Applied Optics, vol. 23, pp. 2201-2208, 1984/07/01 1984.

[11] K. Schäfer, J. Heland, D. H. Lister, C. W. Wilson, R. J. Howes, R. S. Falk, et al., "Nonintrusive optical measurements of aircraft engine exhaust emissions and comparison with standard intrusive techniques," Applied Optics, vol. 39, pp. 441-455, 2000/01/20 2000.

[12] J. D. Black, J. Delhay, P. Desgroux, and M. P. Johnson, "In-Situ Laser-Induced Incandescence of Soot in Large Civil Aeroengine Exhausts," in 26th AIAA Aerodynamic Measurement Technology and Ground Testing Conference, ed: American Institute of Aeronautics and Astronautics, 2008.

[13] J. Delhay, P. Desgroux, E. Therssen, H. Bladh, P.E. Bengtsson, H. Hönen, et al., "Soot volume fraction measurements in aero-engine exhausts using extinctioncalibrated backward laser-induced incandescence," Applied Physics B, vol. 95, pp. 825-838, 2009.

[14] J. D. Black and M. P. Johnson, "In-situ laserinduced incandescence of soot in an aero-engine exhaust: Comparison with certification style measurements," Aerospace Science and Technology, vol. 14, pp. 329-337, 7// 2010.

[15] D. McCormick, K. B. Ozanyan, J. D. Black, and Y. Feng, "In-situ soot particle sensing in an aero-engine exhaust plume," in IEEE Sensors 2013 2013, pp. 12541257.

[16] F. Hindle, H. McCann, and K. B. Ozanyan, "First demonstration of optical fluorescence auto-projection tomography," Chemical Engineering Journal, vol. 77, pp. 127-135, Apr 152000.

[17] K. B. Ozanyan and H. McCann, "Efficiency and data correction for OFAPT sensors with fiber receivers," IEEE Sensors Journal, vol. 5, pp. 195-202, Apr 2005.

[18] P. Wright, E. Fisher, and H. McCann, "Optical Design Considerations for Chemical Species Tomography in a Jet Exhaust Plume," in Imaging and 
Applied Optics 2014, Seattle, Washington, 2014, p. JTu4A.2.

[19] D. McCormick, M. G. Twynstra, K. J. Daun, and H. McCann, "Optimising laser absorption tomography beam arrays for imaging chemical species in gas turbine engine exhaust plumes," in WCIPT7: 7th World Congress on Industrial Process Tomography, Krakow, Poland, 2013, pp. 505-514.

[20] V. S. Sirazetdinov, "Experimental study and numerical simulation of laser beams propagation through the turbulent aerojet," Applied Optics, vol. 47, pp. 975985, 2008/03/01 2008 .

[21] L. C. Andrews and R. L. Phillips, Laser beam propagation through random media vol. 1: SPIE Press, Bellingham, WA., 2005.

[22] J. Kliment and P. Wright, "Optical Design Considerations for Optimising the Transmittance of a Laser Subjected to a Jet Exhaust Plume," presented at the IOP Combustion Workshop, Loughborough, UK, 2015.

[23] J. D. Black, "Fiber Lasers as a Source for LaserInduced Incandescence in Practical Applications," in Lasers, Sources and Related Photonic Devices, San Diego, California, 2010, p. LWB5.

\section{BIOGRAPHY}

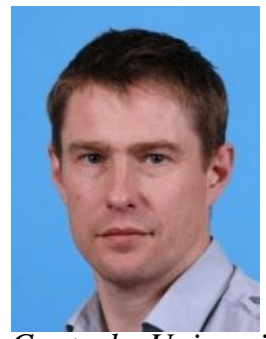

Paul Wright (M'14) received the B.Sc. degree in pure and applied physics from the University of Nottingham, U.K., and the Ph.D. degree in physics from the University of Exeter, U.K., in 1993 and 1997, respectively. He was a Lecturer in the Division of Measurement and Control, University of Teesside, before spending five years with Land Infrared as a Project Engineer working primarily on industrial applications of optical radiometry. He joined the University of Manchester, Manchester, U.K., in 2002, where he is currently a Lecturer. He has designed numerous optical and electronic instruments and co-authored publications on near-IR thermometry, optical tomography and medical instrumentation. His work has been recognized with the Maurice Beck Prize for best paper at the 5th WCIPT (Bergen, 2007) and best poster at Photon 06 (Manchester, 2006).

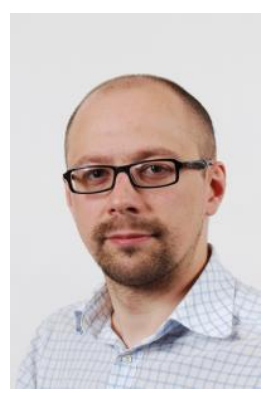

David McCormick (M'13) received the B.Eng. degree in electronic systems engineering and the Eng.D. degree in electrical and electronic engineering from the University of Manchester, UK, in 2006 and 2011 respectively. He also received the Pg.Dip degree in management sciences from Manchester Business School in 2008. Following 10-years working in industry for several large engineering organizations and UK-based SMEs, between 2012 and 2014 he was a postdoctoral researcher working on the FLITES project. Since 2014, he has been a Lecturer with the School of Electrical and Electronic Engineering at the University of Manchester, UK. His research interests include aerospace combustion diagnostics and optical and electrical tomography. Dr. McCormick is a Chartered Engineer with the Institution of Engineering and Technology and was elected a Whitworth Senior Scholar in 2012. His awards include the Worshipful Company of Scientific Instrument Makers Beloe Fellowship 2013-14, the Whitworth Visionary Award 2012 and a Whitworth Senior Scholarship Award (both from the Institution of Mechanical Engineers).

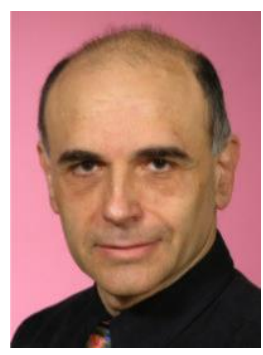

Krikor B. Ozanyan (M'1995, SM'2003) received his MSc degree in engineering physics (semiconductors) and $\mathrm{PhD}$ degree in solid-state physics, in 1980 and 1989 respectively, from the University of Sofia, Bulgaria. He has held previous academic and research posts in the University of Sofia, The Norwegian Institute of Technology (Trondheim, Norway), the University of Hull (UK), and the University of Sheffield 
(UK), working on projects ranging from Brewster-angle mid-IR spectroscopic ellipsometry and electron confinement in quantum wells and barriers, to the demonstration of the lasing at $333 \mathrm{~nm}$ from strained $M Q W Z n C d S / Z n S$ structures and in-situ real-time optical monitoring of growth of III-V semiconductors in MBE and MOCVD reactors. His current interests are in the area of photonic sensors and indirect imaging (tomography) by optical modalities, signal processing for optical experiments, and spectroscopy with ultrafast laser sources. He is currently Head of Sensors, Imaging and Signal Processing at the University of Manchester and Visiting Professor at the University of Bergen, Norway. Professor Ozanyan is Fellow of the Institute of Engineering and Technology, (UK, formerly IEE) and Fellow of the Institute of Physics (UK). He was Distinguished Lecturer of the IEEE Sensors Council in 2009-2010, Guest Editor of the IEEE Sensors Journal Special Issues "Sensors for Industrial Process Tomography" in 2005 and "THz Sensing: Materials, Devices and Systems" in 2012. He is currently Editor-inChief of the IEEE Sensors Journal.

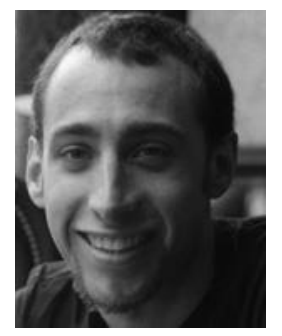

Edward Fisher (M'08) works as a post-doctoral research assistant in the Agile Tomography group within the institute of digital communications (IDCOM). His specialisation and research centre on imaging systems from single-photon sensor development, through to data acquisition and signal processing. He has a particular interest in modelling and optimisation for system design, along with specifications engineering and the implementation of reconfigurable, agile distributed data acquisition and computation systems. Recently centring on mixed-signal design, he has concentrated on including design for test, design for manufacture and design for mechanical considerations, into system development.

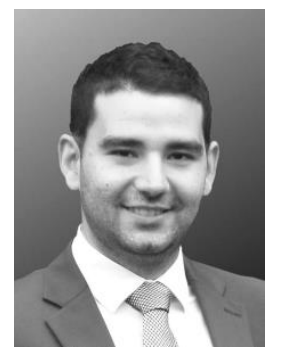

Stylianos-Alexios Tsekenis (M'15) was born in Athens, Greece. He received the BEng and EngD degrees in electrical and electronic engineering from the University of Manchester, UK in 2009 and 2013 respectively. He received the Pg.Dip degree in Enterprise management from Manchester Business School in 2011.In the past he has held posts at Intel Corporation, Royal Dutch Shell plc. and Blaupunkt GmbH, developing instrumentation systems that are now in world-wide use. He has provided technology and bespoke design consultancy services to clients in the events and motorsport industries and is the co-founder of SALTechips. In 2014, he joined the Agile Tomography Group at the University of Edinburgh, UK as a Research Associate. His current $R \& D$ interests are optical tomography systems to image the spatio-temporal distribution of gases. The systems are used to advance automotive, marine and aero engine technologies in order to reduce emissions and optimise energy efficiency. Dr Tsekenis has been awarded the Sir William Siemens medal (Siemens UK, 2008), the Dick Cleland Prize (University of Manchester, 2009) and the Innovation Prize (China International Transducer \& Sensor Contest, 2014). He represented the University of Manchester at the Global Young Scientist Summit (National Research Foundation Singapore, 2013) and is a Member of the Institution of Engineering and Technology since 2005.

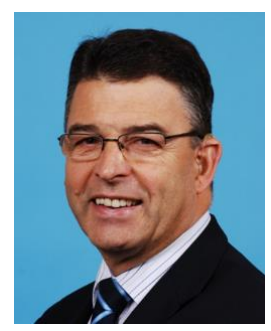

Hugh McCann received the B.Sc. and Ph.D. degrees from the University of Glasgow, Glasgow, U.K., in 1976 and 1980, respectively. He was appointed Professor of Tomographic Imaging and Head of the School of Engineering at The University of Edinburgh, Edinburgh, Scotland, U.K. in 2013. From 1996 - 2013, he was Professor of Industrial Tomography at the University of Manchester, Manchester, U.K., following ten years in $R \& D$ at the Royal Dutch/Shell Group. He worked in highenergy particle physics for ten years at Glasgow, Manchester, CERN (Geneva, Switzerland) and DESY (Hamburg, Germany). He has extended industrial tomography to provide specific chemical contrast using high-speed all-opto-electronic techniques, and has developed electrical impedance tomography for medical applications, collaborating intensively with users in both academia and industry. He was Head of the School of Electrical and Electronic Engineering at Manchester (1999-2002), then chaired the U.K. Professors and Heads of Electrical Engineering (2003-2005) and the Virtual Centre for Industrial Process Tomography (20052009). Prof. McCann was elected a Fellow of the Royal Academy of Engineering in 2009.

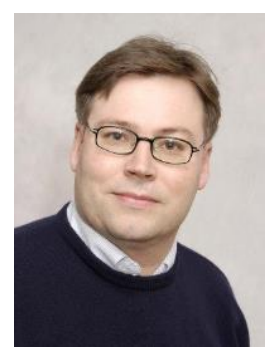

Johan Nilsson is a Professor at the Optoelectronics Research Centre (ORC), University of Southampton, England. In 1994, he received a doctorate in Engineering Science from the Royal Institute of Technology, Stockholm, Sweden, for research on optical amplification. Since then, he has worked on optical amplifiers and amplification in lightwave systems, optical communications, and guided-wave lasers, first at Samsung Electronics and later at ORC. His research has covered system, fabrication, and materials aspects of guided-wave lasers and amplifiers, and in particular device aspects of high power fiber lasers and erbiumdoped fiber amplifiers. He is leading ORC's high-power fiber laser group which, in recent years, demonstrated a number of world-firsts and world-records in the field, including the first single-mode $\mathrm{kW}$ fiber laser and the first cladding-pumped fiber Raman laser. He has published nearly 400 scientific articles and has taught several short courses on fiber lasers and amplifiers. He is a fellow of 
the OSA, a life member of the SPIE, a consultant to, and co-founder of, SPI Lasers, and a member of the advisory board of the Journal of the Optical Society of Korea. In addition, he was guest editor of two issues on high-power fiber lasers in IEEE Journal of Selected Topics in Quantum Electronics in 2009. He has also been active in the organization of several conferences and meetings, and is a former chair of the Laser Science and Engineering technical group in OSA's Science and Engineering Council. At present he is a member of the technical program committee of the Europhoton and the Optical Instrument and Technology conference.

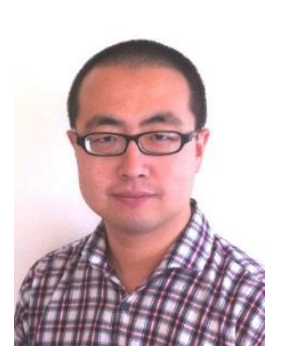

Yutong Feng received the B.S. degree in applied physics from Northwest University, Xi'an, China, in 2004 and the Ph.D. degree in optical engineering from Shanghai Institute of Optics and Fine Mechanics, Chinese Academy of Sciences, Shanghai, China, in 2009. Between 2009 and 2012, he was a Research Assistant at North China Research Institute of Electro-Optics, Beijing, China. He is currently a postdoctoral research fellow at the Optoelectronics Research Centre, University of Southampton, UK. His research interest includes high power fibre lasers and amplifiers, nonlinear fibre optics, systems and applications aspects.

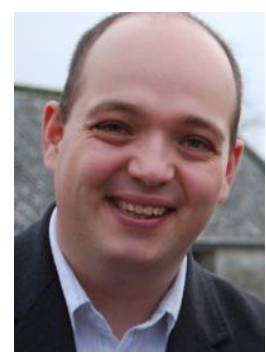

Mark Johnson has worked in the in the field of aircraft gas turbines emission measurement for over 15 years. He received his B.Sc. (Physics) and Ph.D from the University of Reading, Reading, UK, in 1998 and 2003 respectively. He originally specialised in aircraft gas turbine particulate emissions measurement research, and then as a Research Fellow performed research into aircraft engine remote sensing of trace hydrocarbons using FTIR technique under the EU project AEROTEST. Further academic research opportunities included laser induced incandescence aircraft engine remote sensing and contrail formation experiments at Rutherford Appleton Laboratory. He was appointed aviation emissions measurement specialist by Rolls-Royce UK in 2007, and now has a global emissions measurement expert role across all Rolls-Royce transportation sectors. He has practically applied emission certification standards, as well as developed aviation industry emission measurement practices using a wide-range of new instrument technology through research, managing and co-ordinating international engine and combustor emission tests, and collaborating globally across academia and industry. He has participated and been technical lead in a number of EU framework projects and involved in a number of North American and NASA aircraft emission projects. He is a member of SAE-E31, an Industry member of ICAO CAEP
WG3 and an Institute of Physics member. He has authored or co-authored a number of emission measurement scientific publications and aviation regulatory papers and standards.

John D. Black received B.Sc. and Ph.D. degrees in chemistry from the University of Glasgow, in 1971 and 1975. Following postdoctoral posts at Universities of Southampton and Southern California, he joined RollsRoyce plc in 1981 and worked in their Strategic Research Centre until retirement in 2012. He was awarded a Royal Society Industry Fellowship in 2009 and spent the following two years on secondment at University of Manchester. Dr. Black is a member of the SAE E31 committee which advises ICAO on methods of measurement of aero-engine exhaust emissions. He pioneered the application of LII for in-situ soot particle measurement in aero-engine exhausts through three EU funded collaborative programs and instigated the current UK FLITES project for non-intrusive mapping of aeroengine exhaust emissions.

Michael Lengden received the M.Phys. degree in physics and the Ph.D. degree from the University of Manchester, Manchester, U.K., in 2001 and 2006, respectively, where he was engaged in stepwise excitation of atomic and molecular metastable states. He was an Applications Engineer at the Laboratory Impex Systems, Ltd., prior to becoming a Research Fellow in the Centre for Microsystems and Photonics at the University of Strathclyde between 2007 and 2010. He is currently a Lecturer in the EEE Department, University of Strathclyde, Glasgow, U.K., where he is engaged in hightemperature spectroscopy measurements using tunable diode laser spectroscopy. His current research interests include new techniques in tunable diode laser spectroscopy for concentration and pressure measurements in harsh environments, such as solid oxide fuel cells and aeroengines.

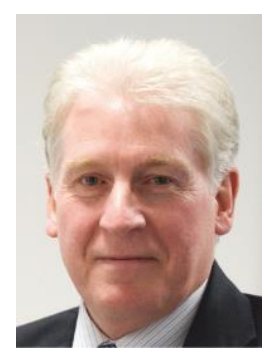

Walter Johnstone received the B.Sc. (Hons.) degree in chemical and material sciences and the Ph.D. degree in laser physics from the University of Strathclyde, Glasgow, U.K., in 1977 and 1982, respectively. From 1980 to 1986, he held Project Engineering and Senior Technical Management posts at Pilkington Optronics, Ltd. (now Thales) and Logitech, Ltd. In 1986, he joined the University of Strathclyde where he is currently Vice Dean of the Faculty of Engineering and a Professor of Photonic Systems in the Department of Electronic and Electrical Engineering. Since 1994, he has been a Director of OptoSci, Ltd., Glasgow, where he has been instrumental in bringing a number of photonics products to market. His work has led to more than 200 technical publications and several patent applications. His current research interests include optical waveguide components, fiber lasers, distributed fiber sensing 
systems, and optical gas sensing.

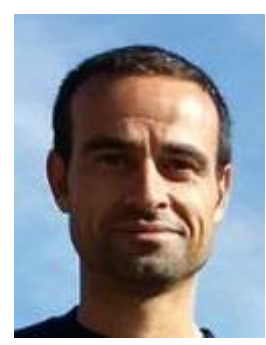

Victor Archilla is the head of the instrumentation and experimental measurement techniques laboratory at INTA Turbojet engine Test Centre, received the B.S. in telecommunications in 1999 at the Polytechnic University of Alcalá de Henares and the M.S. degree in renewable energy in 2010. He is currently pursuing the Ph.D. degree in environment science and engineering at San Pablo CEU University. He has huge experience in instrumentation sensors, data analysis methods and test protocols to contribute to the engineering determination of the engine performance. He was member of the RTO-AVT-180 - Gas Turbine Engine Test Cell Instrumentation and the RTO-AVT_128-More Intelligent Gas Turbine Engines committees and he is interested in advanced test cell instrumentation concepts and research in physical characterization and chemical composition of both volatiles and non-volatile particulate matter.

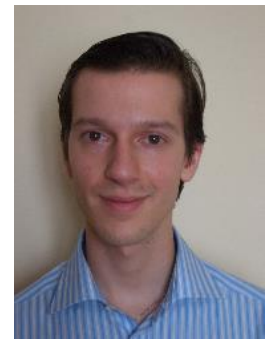

Álvaro González-Núñez became an Aeronautical Engineer and received the Master degree in propulsion in the E.T.S.I.Aeronáuticos, in the Universidad Politécnica de Madrid (UPM) in 2005. He worked as a process engineer for advanced composites in Aries Complex for a year before becoming a test engineer in the INTA (Instituto Nacional de Técnica Aeroespacial) Test Cell, where he is currently working. During the past nine years he has collaborated with Rolls Royce in the testing of the Trent family of jet engines (T500, T700, T800, T900, T1000 \& T-XWB) in both certification and development programs. 